ductory text relating to education in bioethics, we might have expected a broad introduction to the kinds of issues with which teachers of ethics in medicine should be concerned and to some ways in which they might build ethics into the education of doctors, nurses and other health care workers.

Grafius does give an introduction of a kind to education in biomedical ethics. For example, she gives an overview of some of the topics that might feature in a biomedical ethics education programme, though it is worth noting that most of these, other than issues of consent, hover around questions relating to death and terminal illness. She offers some guidance about the construction of such a programme and gives a step by step guide to a "process for ethical thinking and reflection" - a kind of "beginner's guide to ethical decision-making". This detailed procedural guide to ethical thinking might be particularly useful for those whose experience of wrestling with the dilemmas thrown up by practice is limited, and for practitioners who feel paralysed by their inability to make ethical choices. They should, of course, beware of the possibility of falling into the trap of believing that having followed the procedure laid down, the decisions they make will necessarily be the right ones; in any event such an approach, though useful in the initial stages of developing one's ability in ethical thinking, must in my view, eventually be laid aside.

Grafius has written Ethics for Everyone from a particular professional and cultural context and much of what she has to say about bioethics education - for example, about its scope, when it should take place, and for whom it should be provided, is perhaps of limited interest to those who do not work in similar contexts. The book contains no index, which is always a source of some annoyance. It does, however, contain a substantial bibliographical section containing references to texts (both general and topic-specific), videos and journals dealing with medical ethics; interestingly, though some non-North American books appear, the fournal of Medical Ethics is omitted from the list of relevant periodicals as is the journal Bioethics, which I would consider an important international contribution to any library serving health care ethics education. Lists are also given of centres dealing in issues in bioethics; again the focus is on North American centres.
This book is best regarded as a source for those who are already involved in teaching ethics to health care professionals. For example, it is a source of ideas for those who are unable to develop pedagogical tools of their own, or who want to learn some new tricks. One such idea is that of the "biomedical ethics grand round" - a formal affair where topics or particular cases are presented and discussed in an organised and formal interdisciplinary setting. One possible advantage of such an approach to working on ethical problems, is that the formality of the setting might make it easier for colleagues of different disciplines and different status to negotiate solutions, if solutions there are, to particular problems. On the other hand a formal setting might help to perpetuate certain myths, including the idea that seniority and status necessarily convey moral rightness.

Further to her discussion of biomedical ethics "grand rounds" Grafius offers a number of other "educational tools" designed to help participants in classes to become aware of various things - mostly, but not exclusively about themselves about their attitudes to death and mortality, about the source and nature of their moral beliefs, and about their relationship to significant others. Many of the tools offered focus on aspects of death and dying and this brings me to a weakness in the book as an introduction to biomedical ethics education in general - the limited range of issues that are addressed.

Following on from the discussion of these exercises is a chapter about the use of role play, which includes many vignettes which are suggested as the basis for role plays of various kinds. Role play is a valuable tool which can have great power to move but, perhaps as a consequence of this, must be handled carefully. As was the case with the educational tools I have already discussed, I am not convinced that Grafius gives sufficient guidance about its use. She offers both an overview of role play and its uses and some instructions about how to go about setting role-playing situations. However, I do not think this is sufficient to allow those who might use this book as an introduction to biomedical ethics education to use the interesting scenarios she offers to good effect, and more importantly, safely. My view is that role play is used too lightly by too many people who would do well to sensitise themselves to its power. Grafius makes clear that she does not think that role play should be used in isolation, but rather as part of a broader educational experience. In my view it should only be used by those who have given considerable time to learning how it might be used, perhaps as part of a course of study in dramatherapy or psychodrama.

Perhaps the most useful feature of this book is the fact that it contains some ready-made topics for discussion or, in the right hands, for exploration through action - whether in a mock "grand round", through role play, or through other narrative forms. All of this material would have been much more useful if it had been accompanied by discussion of the ethical issues raised, and by more substantial discussions of the ways in which the material - in particular the pot pourri of case studies and vignettes offered for role play - might be used.

\section{Long-term Care Decisions: Ethical and Conceptual Dimensions}

Edited by Laurence B McCullough and Nancy L Wilson, Baltimore, Maryland, Johns Hopkins University Press, 1995, 246 pages, $£ 33$ hc.

This book is valuable reading for anyone working in the field of long-term care, and indeed for anyone working in the field of bioethics. The book provides a thorough and systematic analysis of the complex issues and influences involved with long-term care decision-making, and offers recommendations for adequately accounting for the importance of these. The value of the book can be measured by the fact that one can find oneself disagreeing with a particular substantive position which is proposed, while simultaneously realising the important contribution made in identifying the issue to be addressed.

The book is divided into five sections, each containing two to three chapters. The first section of the book examines historical and social forces which have influenced long-term care. 
The first chapter offers an historical perspective, while the second chapter examines the current system for longterm care in the United States. The second section of the book then examines the issues involved in long-term care decisions for case managers. These are referred to as "practice considerations". The emphasis of these chapters is on the complex nature of decision-making in the long-term care setting, and the balancing of such considerations as autonomy, family, and institutional and policy constraints. The third section challenges several traditional concepts in long-term care, such as autonomy, safety and independence, and the ways in which we attach importance to each. The authors in this section offer alternative conceptual frameworks which more adequately capture the practical concerns of the long-term care setting. The fourth section examines the role of the family in making long-term care decisions: what do married couples owe each other; what considerations affect children in making long-term care decisions for elderly parents; how should we address conflicts of interest for family members participating in long-term-care decisions. The final chapter critiques what it describes as the "reactive approach" to ethical conflicts in contemporary bioethics, and argues for a "preventive approach" as more appropriate in the long-term-care setting.

Throughout the book, one is struck by the connections which are made by authors to other work in the book. The reader gets the feeling that the book resembles more a co-authored work (with over a dozen co-authors!) than an anthology. This helps the book maintain a focus and gives the reader a feeling that the book is making progress towards a consistent method for addressing ethical conflicts in a long-term-care setting. This is sorely lacking in many anthologies of this type, which often resemble a collection of very loosely related independent papers.

While the book focuses on ethical decision-making in long-term care, many of the challenges raised to traditional concepts in bioethics can easily be expanded (and indeed, sometimes are) to challenge the adequacy of these concepts, not only for ethical practice in a long-term-care setting, but also for the adequacy of these concepts for practical use in bioethics in general. While this relationship is sometimes addressed, I found myself wishing for an even broader analysis of this. I take this, however, as a positive aspect of the book, as it spurs reflection on the limits and applicability of certain traditional concepts in bioethics, without losing focus on the specific issues at hand.

In general, I believe this to be an outstanding book that will reward careful reading and reflection. As a whole, the book provides a wonderful framework for understanding the complex nature of long-term-care decision-making. I recommend this book highly.

THOMAS MAY
Memorial Medical Center, Springfield,
Illinois, USA

\section{The Older Person: Consent and Care}

Report of the British Medical Association and the Royal College of Nursing, London, British Medical Association, 1995, 63 pages, $£ 6.95$ (BMA/RCN members $£ 5.95)$.

\section{Assessment of Mental Capacity: Guidance for Doctors and Lawyers}

Report of the British Medical Association and The Law Society, London, British Medical Association, 1995, 152 pages, $£ 8.95$ (BMA members $£ 7.95$ ).

Questions about the rights and capacities of a number of disadvantaged groups - young people, older people, people with learning disabilities, people with mental disorders - to manage their affairs and to give or withhold consent to medical treatments have quite rightly been gaining increasing public and professional notice. Discussion in the media has been focused by such high profile cases as that of Tony Bland, for whom a judgment was sought as to the legality of withdrawing his life support system, given his persistent vegetative state. Widespread discussion of such questions is very welcome

For carers and professionals working with these groups of people, decisions about their capacity to determine their affairs and treatment frequently have to be made, even over such day-to-day questions as how far a person with dementia should be required to accept personal care when he or she may not understand or accept the need for it. One of the strengths of The Older Person is that it emphasises the enormously wide range of clinical situations in which ethical decisions about consent need to be made, and shows how the process of seeking a patient's consent must be very flexible in order to maximise the ability of the patient to form an opinion and express it. It is not just a question of asking for permission: the patient has a right to a sustained attempt to explain what is being offered in terms which he or she can understand, and, if necessary, a change to the immediate environment to help the patient to make an appropriate decision. The book shows how good ethical practice and good clinical practice are closely related.

The Older Person focuses "mainly on the ethical problems which arise daily for the minority of older people who require care and treatment, particularly problems related to consent, and our ethical and legal duties as professionals towards these people". A wide range of issues is covered.8 Chapter one describes who "older people" are, pointing out that manyea of their needs are related as much to negative societal attitudes as to needs arising directly out of their age alone. The next four chapters are all concerned with consent. Chapter two considers how to promote patient autonomy and includes a valuable discussion on how to maximise the older person's capacity to make decisions. Chapter three, using the definition of consent given in the code of practice of the Mental Health Act, 1983, describes in practical but general terms how to assess a person's capacity to consent, and goes on to describe the ethical and legal basis of treating people who either cannot or will not give consent. Advance statements, do-not-resuscitate orders, consent to research and legal liability of providers of care are also discussed. Chapter four considers confidentiality and the circumstances under which it may be desirable to disclose information, and chapter five has a short but practical discussion of the principles governing the use of restraints. Chapter six is a concise (six-page) summary of earlier chapters

The great merits of this book are its clarity, accessibility and brevity. It covers, just as it claims, a wide range of ethical issues which arise constantly in the day-to-day care of older people. 